\title{
“TOO MUCH MEDICINE": INSIGHTS AND EXPLANATIONS FROM ECONOMIC THEORY AND RESEARCH
}

\section{http://dx.doi.org/10.1016/j.socscimed.2017.01.020}

First and corresponding author:

Mr. Martin Hensher

School of Medicine

University of Tasmania

Private Bag 34

Hobart TAS 7000

Australia

Email:_martin.hensher@utas.edu.au

Professor John Tisdell

Tasmanian School of Business and Economics

University of Tasmania

Private Bag 84

Hobart TAS 7001

Australia

Email: john.tisdell@utas.edu.au

Professor Craig Zimitat ${ }^{1}$

School of Medicine

University of Tasmania

Private Bag 34

Hobart TAS 7000

Australia

Email:_craig.zimitat@curtin.edu.au

${ }^{1}$ Present address:

Curtin Learning and Teaching

Curtin University

Perth WA 6150

Australia 


\title{
"Too much medicine": insights and explanations from economic theory and research.
}

\begin{abstract}
Increasing attention has been paid in recent years to the problem of "too much medicine", whereby patients receive unnecessary investigations and treatments providing them with little or no benefit, but which expose them to risks of harm. Despite this phenomenon potentially constituting an inefficient use of health care resources, it has received limited direct attention from health economists.
\end{abstract}

This paper considers "too much medicine" as a form of overconsumption, drawing on research from health economics, behavioural economics and ecological economics to identify possible explanations for and drivers of overconsumption.

We define overconsumption of health care as a situation in which individuals consume in a way that undermines their own well-being. Extensive health economics research since the 1960s has provided clear evidence that physicians do not act as perfect agents for patients, and there are perverse incentives for them to provide unnecessary services under various circumstances. There is strong evidence of the existence of supplier-induced demand, and of the impact of various forms of financial incentives on clinical practice. The behavioural economics evidence provides rich insights on why clinical practice may depart from an "evidence-based" approach. Moreover, 
behavioural findings on health professionals' strategies for dealing with uncertainty, and for avoiding potential regret, provide powerful explanations of why overuse and overtreatment may frequently appear to be the "rational" choice in clinical decision-making, even when they cause harm. The ecological economics literature suggests that status or positional competition can, via the principal-agent relationship in health care, provide a further force driving overconsumption.

This novel synthesis of economic perspectives suggests important scope for interdisciplinary collaboration; signals potentially important issues for health technology assessment and health technology management policies; and suggests that cultural change might be required to achieve significant shifts in clinical behaviour.

\section{Key Words}

Too much medicine

Health care overconsumption

Overtreatment

Overdiagnosis

Health economics

Behavioural economics

Ecological economics 


\section{Introduction}

In recent years, a movement of health professionals, researchers and consumer advocates has coalesced, focusing on the harms of overdiagnosis and overtreatment (Macdonald \& Loder 2015). This movement has adopted the label "too much medicine" to refer to the general phenomenon of unnecessary investigations and interventions given to patients who will not benefit from them, and who will be exposed to the risk of harm and medicalisation along the way (Carter et al. 2015). The primary motivation for this growing attention is the desire to avoid exposing patients to unnecessary harm; however, this phenomenon also possesses a significant economic dimension (Welch, Schwartz \& Woloshin 2011).

Certain aspects of this phenomenon have received direct attention from an economic perspective, for example overutilisation (Behnke et al. 2013) and "low value care" (O'Callaghan, Meyer \& Elshaug 2015; Schwartz et al. 2014). Yet the overall concept of the harmful overconsumption of health care has received little attention from health economists, and appears to be significantly less prominent in the cost-effectiveness and health technology assessment literatures than might have been expected given its obvious implication - if resources are currently expended which yield no benefit (or cause harm), they could clearly be conserved with no loss of benefit to patients. 


\section{Methods}

A detailed literature search was undertaken to review the definitions and characteristics of different forms of overconsumption of healthcare, in order to develop a working definition of this phenomenon. The online databases Web of Science (Core Content) and PubMed were searched using the following terms: overdiag* NEAR/10 defin*; overdiagnosis NEAR10 definition; overtreat* NEAR/10 defin*; overtreatment NEAR10 definition; overus* NEAR/10 defin*; overuse NEAR10 definition; overutil* NEAR/10 defin*; overutil $^{\star}$ NEAR10 definition. EconLit was then searched to provide an entry point to the wider health economics, behavioural economics, ecological economics, and sustainable consumption literatures, using the following search terms: consumption AND (health OR healthcare) AND theory; overconsumption; sustainable AND consumption.

In addition, hand searches for follow-on references were undertaken of books and articles already in hand, and from key texts identified in the online search. The paper then reviews and discusses the literature thus identified, first to situate these phenomena in the broader economic context, and then to examine potential economic explanations emerging from this review. Key findings and their possible implications are then summarised, as a foundation for commencing a broader debate on the economics of the overconsumption of health care. 


\section{Defining Overconsumption in Health Care}

The largest category of literature identified related to overdiagnosis, most frequently in the context of cancer screening programmes ((Marcus et al. 2015; Marmot et al. 2012), but also more widely (Carter et al. 2015; Moynihan, Henry \& Moons 2014; Welch, Schwartz \& Woloshin 2011). Overdiagnosis occurs when 'illnesses' are diagnosed which - if they had remained undiagnosed - would never have caused patients harm, with the consequence that patients are exposed to unnecessary treatments for which risks outweigh benefits.

A number of authors consider the problem of overtreatment (Carter et al. 2015; Moynihan, Henry \& Moons 2014), or the use of unnecessary clinical services or interventions which provide negligible benefit, so that harm outweighs any small benefit in virtually all cases. This definition is highly contiguous with definitions of overuse (Beckman 2011; Segal et al. 2015) or overutilisation (Behnke et al. 2013). Overuse (or overtreatment) thus represents an "error of commission" in which services with a poor benefit to risk profile are provided to patients (Chan et al. 2013).

A closely related concept which begins to incorporate aspects of cost or value is that of low value care, defined as "...practices that are, at best, of little to no clinical utility and, in certain situations, harmful" (O'Callaghan, Meyer \& Elshaug 2015 , p. 175) or “...care that was likely to provide minimal or no 
benefit on average" (Schwartz et al. 2014, p. 1073). In similar vein is the idea of questionable care , described most simply as "...treatments...that do not work, and may do harm" (Duckett, S et al. 2015, p. 2).

The concept of "pharmaceuticalisation" was also identified in the recent literature as involving "...the transformation of human conditions, capabilities and capacities into opportunities for pharmaceutical intervention" (Gabe et al. 2015, p. 193) . This concept has also been related to situations in which medicine use ceases to be rational, fails to confer benefits and/or risks harms without concomitant benefits (Busfield 2015), noting the growing importance of pharmaceuticalisation as medications are increasingly used preventively in broad populations, not just in the sick. Pharmaceuticalisation is clearly a cousin of "overmedicalisation", most famously propounded in the 1970s by Ivan Illich (Illich 1976). This can be described as “...altering the meaning or understanding of experiences, so that human problems are re-interpreted as medical problems requiring medical treatment, without net benefit to patients or citizens" (Carter et al. 2015, p. 5).

A common feature of all these terms is that they describe phenomena in which resources are used unnecessarily, with little or no benefit, and often with potential to cause harm.

\section{Contextualising "too much medicine' within the economics literature}

As a first step, it is helpful to consider how the phenomenon of "too much medicine" relates to a number of core concepts within the ecological and 
sustainable economics and health economics literatures, before reviewing specific parts of this literature in more detail. It has long been recognised that health care markets display a number of significant special characteristics that differentiate them from a perfectly competitive market (Arrow 1963), including pervasive uncertainty, unavoidable information asymmetries, and the need for principal-agent relationships. Subsequent discussion will draw heavily on these identified departures from the "standard" model of perfect competition.

Implicit in the very idea of "too much medicine" is the need to ask the question: too much relative to what? An orthodox economic approach to this question implicitly compares the consumer surplus generated by the actual health care market (with all its acknowledged imperfections) with the consumer surplus that would have been generated by a perfectly competitive market (Peacock \& Richardson 2007). A second approach to this question argues that moral hazard means those with insurance will consume more health care than if they were uninsured - and that the overall effect of such additional consumption on economic welfare is negative (Frick \& Chernew 2009). Neither of these approaches explicitly address any negative impacts of overconsumption, but appeal directly to orthodox notions of consumer surplus.

By contrast, a third implicit approach to the question of "how much is too much" compares actual consumption with need for care as defined by appropriate expert evidence or opinion (Boulding 1966; Deber, Hollander \& 
Jacobs 2008). The defining feature "too much medicine" set out above is the provision of treatments which provide no significant benefit and may also cause harm - so by implication, such treatments should never be considered as "needed" if evaluated correctly. Similarly, when viewed through the lens of cost-effectiveness analysis, "too much medicine" will deliver no incremental benefits (and may reduce overall benefits through causing harm), but will incur the additional costs of these unnecessary interventions. It therefore represents care that is less effective and more costly than available alternatives - hence it will always be dominated in cost-effectiveness terms by other strategies (Drummond et al. 2015).

The ecological and sustainable economics literatures offer some alternative approaches to considering the same question, i.e. overconsumption relative to what benchmark? Much of this literature focuses on aggregate measures, to consider whether total consumption is or is not excessive in relation either to intertemporal social welfare (i.e. maximizing the present value of current and future utility from consumption) or sustainability, i.e. the ability of the economy to maintain human living standards or social well-being without their declining over the long run (Arrow et al. 2004; Dasgupta 2010). Others explicitly frame this question in terms of whether humanity is consuming too much for the rest of the planet (Daly et al. 2007).

Princen suggests two useful concepts in this space (Princen 1999). He defines overconsumption as being that aggregate "...level or quality of 
consumption which undermines a species' own life support system and for which individuals and communities have choices in their consuming patterns" (Princen 1999, p. 357). Individual or community consumption decisions may be rational, but lead eventually to ecological catastrophe. He also defines an individual level concept, misconsumption, which occurs when individuals consume in a way that undermines their own well-being - "...individual resource-using acts that result in net losses for the individual" (ibid, p. 357). Princen suggests that a critical opportunity therefore emerges in identifying those forms of individual misconsumption (which harm the individual consumer) which also lead to collective overconsumption.

Princen's concepts of overconsumption and misconsumption (Princen 1999) can helpfully frame two alternative lenses for considering the overconsumption of health care. A focus on collective overconsumption requires consideration of health care's overall material or resource throughput (Daly et al. 2007; Sorman \& Giampietro 2013). This perspective accounts for all negative impacts and negative externalities throughout the production chain of health care, incorporating all energy, natural resource consumption and pollution effects - whether or not the end products of health care are beneficial to the health status of individual patients or society as a whole. It is worth noting that the problem of "too much medicine" may itself be a contributor to Daly's aggregate concept of "uneconomic growth" (Daly 2005). According to Daly, uneconomic growth occurs when continuing increases in production (i.e. economic growth) come at a cost in reduced welfare or 
environmental depletion that is greater than the value of the additional production. Increasing overdiagnosis and overtreatment would represent precisely such a phenomenon - excess treatment is counted as contributing to economic growth, but its contribution to well-being is, in fact, zero or negative.

Viewed through the "interpretive layer" of individual misconsumption proposed by Princen (1999) however, the focus narrows to that consumption of health care which results in net losses to the individual. The working definition of "too much medicine" (the consumption of health care that brings risk of harm for little or no appreciable benefit) is, arguably, very much an example of Princen's concept of misconsumption. A focus on misconsumption therefore involves a more specific focus on the costs, harms and benefits of specific interventions. Given the focus of the "too much medicine" movement on preventing individuals from suffering harm through unnecessary treatment, this paper will concentrate on examining health care from the misconsumption perspective - that is, the more direct impact on individual health and wellbeing of "too much medicine" - and will not pursue the aggregate perspective further. It is important to note that Princen's concept of misconsumption does not directly address one important characteristic of health care: the central importance of the agency relationship between patient and health professional. This feature will be seen to be vital throughout the discussion that follows. 


\section{Explaining Too Much Medicine - Insights from Economics}

Why, then, do we appear to misconsume health care, giving rise to the problem of "too much medicine"? From the demand side, we explore whether this is the result of moral hazard. The supply-side concepts of supplier induced demand, the role of payment systems, cost-effectiveness analysis, and the "medical arms race" are then reviewed. This section concludes by examining the application of behavioural economics in this field, and the related concept of competitive or positional competition.

\section{Moral Hazard}

Moral hazard describes the general tendency for the presence of insurance to undermine the incentives to prevent or minimise the cost of the insured risk occurring. In health insurance, moral hazard is more generally referred to as the tendency for individuals to consume more health care when they are insured than they would have done without insurance - because they now face a lower marginal cost of care than if they were uninsured (Pauly 1968). That insurance increases health care utilisation is uncontroversial, theoretically and empirically, and where the benefits of this increased utilisation do not exceed its costs, this will have a negative impact on welfare (Frick \& Chernew 2009), potentially representing a form of misconsumption. However, Frick and Chernew identify a range of factors which may mean that moral hazard does not, in fact, lead to welfare-reducing overconsumption of care. They argue that there is no a priori reason to believe that the quantity of health care that would be purchased without insurance is efficient or optimal. Given the major departures from the competitive market model that 
characterise health care markets, they argue that insurance may inherently be a superior "second best" solution, because the conditions for market optimality do not exist in reality. Finally, they cite a range of evidence that insurance supports individuals to consume effective and welfare-enhancing treatments, and that removal of insurance (or the existence of high co-payments) indiscriminately reduces use of both high and low value treatments. These conclusions appear to have been borne out by the US experience of "consumer directed care" (an attempt to design health plans that minimise moral hazard through both financial and information features). Consumer directed health plans appear to have decreased overall expenditures, but not to discriminate well between necessary care and low value care (Bundorf 2016; Buntin et al. 2011).

\section{Supplier Induced Demand}

A recent systematic review of the literature on supplier induced demand (SID) (Leonard, Storduer \& Roberfroid 2009, pp. 121-122) defines it as “...the phenomenon of physicians deviating from their agency responsibilities to provide unnecessary care with the main objective of increasing their own pecuniary resources." Their review concludes that, from the 25 studies ultimately included, the existence of SID is a "straightforward" finding, with strong supporting evidence. Broadly, they concluded that, as the supply of physicians (or "physician density") for a given population increases, physicians will increase the number of interventions or treatments per patient, to maintain a target income in the face of increased competition. 
The existence of SID has a number of potentially significant implications for the overconsumption of health care. Its existence suggests that the observed outcomes of health care markets "... may have more to do with producer rather than consumer welfare" (Peacock \& Richardson 2007, p. 268). It suggests that power and asymmetric information enable physicians to induce demand by recommending procedures or interventions even when the clinical evidence suggests that the costs of the procedure to patients outweigh the benefits (Dranove 1988), and is therefore evidence that physicians are not constrained to work as anywhere near perfect agents for patients (Stano 1987). Interestingly, the SID literature has generally not investigated the consequences of SID for patients and society in any detail (Leonard, Storduer \& Roberfroid 2009), with one notable exception (Labelle, Stoddart \& Rice 1994). Labelle et al set out a conceptual framework which allows consideration of the circumstances in which "induced" services do or do not contribute positively to the patient's health status, which potentially allows for the identification of that subset of SID which would constitute misconsumption.

\section{Payments and Financial Incentives}

It has long been recognised that different provider payment mechanisms and systems can generate different levels of utilisation. Two recent reviews provide excellent overviews of common health care provider payment mechanisms and the likely impacts they may have on utilisation rates in both primary health care and hospital systems (Langenbrunner, Cashin \& O'Dougherty 2009; Robertson, Rose \& Kesselheim 2012). In broad terms, 
they show how line-item or global budgets and salaried payment systems tend to encourage under provision; capitation-based systems may incentivise underutilisation or risk selection and "cream-skimming"; while fee-for-service, case-based and per diem payment systems tend to encourage overutilisation. Importantly, they note that different provider payment methods are often combined in different permutations to attempt to mitigate some of the various negative effects that individual methods may bring. Similarly, Deber et al (Deber, Hollander \& Jacobs 2008) provide a useful discussion of how health care payment mechanisms must be linked to consideration of the extent to which any given system seeks to focus on meeting either "needs" (a normatively based assessment of health care requirements) or "demand" (driven by willingness and ability to pay for care).

While these discussions make it clear that a well-designed payment system should seek both to avoid incentives towards unnecessary overutilisation and to avoid rewarding or incentivizing under-utilisation (Langenbrunner, Cashin \& O'Dougherty 2009), it is less clear whether payment systems can really be "fine-tuned" in this regard. In particular, experience to date with payment for performance or quality systems (P4P) suggests they may not be as discriminating as hoped for in their beneficial effects on provider behaviours and utilisation levels (Robertson, Rose \& Kesselheim 2012), or in weeding out "low value care" (Schwartz et al. 2014). 
Beyond the direct action of payment mechanisms, Robertson et al (2012) also summarise the available evidence on the existence of other forms of financial conflict of interest which may affect health care providers' clinical behaviour. They identify strong evidence of substantial impacts on clinical decisionmaking when physicians can self-refer patients to themselves for specialised service provision, and when they can refer patients to facilities or services in which they own a stake - showing that such direct financial incentives can drive excess utilisation when compared to the referral patterns of physicians without these conflicts of interest. They also summarise clear evidence that a range of inducements from pharmaceutical manufacturers have been shown to impact on physician prescribing behaviour, even though physicians are typically unaware that their behaviour is altered by these incentives.

\section{Cost-Effectiveness and Low Value Care}

Overconsumption of health care will tend to be dominated by more costeffective intervention options, as overtreatment generally represents wasteful and cost-ineffective care. Given that cost-effectiveness analysis has been increasingly deployed through systematic approaches to health technology assessment (HTA) in a growing number of countries, it might be reasonable to assume that one of the targets that well-designed HTA processes should seek to sift out should be overdiagnosis and overtreatment.

However, it has been observed (Bryan, Mitton \& Donaldson 2014) that HTA focuses overwhelmingly on the adoption of new technology, with scarcely any 
attention paid to what they describe as "technology management" of existing interventions. This gives rise to a major asymmetry between well-funded and exhaustively developed processes for assessing new technologies, and shoestring or non-existent processes to guide disinvestment from existing (but lower value) technologies (Elshaug et al. 2007). Bryan et al (2014) point out the potential dangers of this systemic bias, which effectively means that new technologies are only assessed once, on entry to the system, and are not subsequently reviewed or managed once in the system. They note particular dangers from "indication creep" - the phenomenon by which a technology is initially assessed and adopted for use in a specific indication and group of patients, but subsequently spreads to wider patient groups and indications, with no further assessment of cost-effectiveness, which may be a key contributor to technology-driven health care cost growth. They also suggest we should beware of technologies subsequently failing to deliver the benefits promised in their initial HTA evaluations once they are deployed at scale in routine practice.

An empirical challenge for cost-effectiveness analysis and HTA systems generally is to develop the capability for assessing the relative costs and effectiveness of interventions in different populations, for different indications, and for differing treatment thresholds, once technologies are already approved and in use. While there are some interventions that simply should not ever be provided to anyone, these are a tiny minority, and likely to be relatively insignificant in cost terms (Duckett, SJ, Breadon \& Romanes 2015; 
Schwartz et al. 2014). The greater prize requires scaling back low value care (Elshaug et al. 2007), which will require nuanced and sensitive analyses to indicate the groups and thresholds in which interventions are more or less cost-effective.

\section{The "Medical Arms Race"}

A small literature from the United States during the 1980s and 1990s considered a phenomenon popularised as the "medical arms race." Robinson and Luft (1985) noted that - contrary to standard economic theory - hospitals in more competitive markets appeared to have higher costs than hospitals with greater monopoly power. They hypothesised that a possible explanation for this phenomenon involved inflationary increases in investment in technology and service intensity to retain market share and physician loyalty (Robinson \& Luft 1985), representing a form of "quality competition" in which "quality" is overproduced through competitive strategy (Dranove, Shanley \& Simon 1992). The extent to which empirical evidence supported this hypothesis was contested by Robinson, Dranove and their respective collaborators. Interest in the issue waned as changes to reimbursement systems and the rise of managed care changed market incentives in the USA, but the possible return of elements of the medical arms race has been noted since (Devers, Brewster \& Casalino 2003).

\section{Behavioural Economics and Health Care}

A different set of insights as to why misconsumption of health care may occur is provided by the behavioural economics (or behavioural theory) literature. 
Over the last three to four decades, increasing evidence has shown that the traditional economic model of the consumer as a rational maximiser simply does not explain actual consumer behaviour, building on earlier ideas of "bounded rationality" and the existence of a variety of mental illusions which affect actual decision-making (Thaler 1980).

Strong evidence shows that individuals consistently display "loss aversion", that is they place a higher value on avoiding a loss than on receiving a gain of equivalent monetary value (Rabin 1998). From loss aversion comes the concept of "regret theory", whereby individuals anticipate possible feelings of regret that might be the consequence of making the wrong choice in a decision process; this "anticipatory regret" then influences their choice, with a strong bias towards minimising potential regret. The scope for regret in medicine is particularly high - uncertainty (e.g. about the patient's true diagnosis) is rife, and the stakes of error are high for patients (Frank 2004). One study explicitly applies regret theory, and the concept of "acceptable regret", to clinical decision making, in the form of clinical decisions about diagnostic testing (Hozo \& Djulbegovic 2008). They concluded that their model could explain why different (and apparently excessive) use of diagnostic testing could in fact represent an entirely rational attempt by physicians to moderate their potential regret to acceptable levels.

Djulbegovic and Paul (2011) explored the inherent limitations of applying general (and often incomplete) evidence to specific patients. It is not possible 
to provide comprehensive evidence on effectiveness and cost-effectiveness for every eventuality, and clinicians are constantly forced to use inductive reasoning to extrapolate from the available evidence to patients who differ from those on whom trials have been performed (Djulbegovic \& Paul 2011). This unavoidable uncertainty is a major force driving variations in practice. They argued that clinicians' responses to this uncertainty in turn drive "indication creep" (the practice of promoting the use of an intervention for offlabel indications) and "prevention creep" (the promotion of tests originally developed to detect symptomatic disease in asymptomatic patients) - both of which will then be promoted by industries who will profit from increased utilisation and sales. Physicians' honest but fallible efforts to deal with imperfect information then combine with their desire to minimise regret as discussed above: they are much more willing to tolerate false-positive errors ("regret of commission") than false-negative errors ("regret of omission"), and interpret limited efficacy evidence liberally, leading to overtreatment (Djulbegovic \& Paul 2011). Unavoidable uncertainty at the individual level may thus lead to overtreatment - both individually and in aggregate.

A final area of insight from the behavioural economics literature concerns the role of biases and heuristics in guiding clinical behaviour. Rabin (1998) summarises a range of biases documented through experimental evidence which might be expected to impact adversely on clinical decision-making, including anchoring to initial (but perhaps wholly inappropriate) levels, failure to account adequately for small numbers or the likelihood of regression to the 
mean, belief perseverance, confirmation bias, hindsight bias and overconfidence in our own judgement or capabilities (Rabin \& Schrag 1999). At the same time, a consistent theme from behavioural science is that human behaviour "...is driven predominantly by automatic and habitual responses, rather than reflective and goal-directed processes" (Fletcher 2014, p. 158).

\section{Competitive and Positional Consumption}

One potential explanation for aggregate overconsumption that has received wide attention in the ecological economics literature over the years shares common links with the beginnings of the behavioural economics movement (Scitovsky 1992). This concept has gone by a number of names, all of which are identifiably related: "positional consumption" (Hirsch 1977), "status consumption" (Scitovsky 1992), "consumption externalities" (Dupor \& Liu 2003), or "status races" (Clark, Frijters \& Shields 2008).

This theory proceeds from the insight that "...as the level of average consumption rises, an increasing portion of consumption takes on a social as well as an individual aspect. That is to say, the satisfaction that individuals derive from goods and services depends in increasing measure not only on their own consumption but on consumption by others as well" (Hirsch 1977, p. 2). As a result, an individual's utility depends not just on their absolute consumption and its direct benefit to them, but on their consumption relative to others, because a key driver of utility is the desire for social status (Clark, Frijters \& Shields 2008; Scitovsky 1992). The goods and services being 
consumed are therefore serving partly as proxies for the social status that individuals really wish to convey. This leads to a trap for both individuals and society: as incomes rise, people will chase each other in consuming more but derive no lasting increase in utility because others' consumption has also risen, so their relative status is essentially unchanged (Clark, Frijters \& Shields 2008). They become habituated to status and are highly averse to loss of status - an upwards ratchet (Scitovsky 1992). In aggregate, this "jealousy" consumption externality (Dupor \& Liu 2003) leads to an equilibrium consumption level higher than the socially optimal level of material consumption were status or positional competition not in play.

It is not immediately clear that consumption of health care may be competitive between individual patients. If, however, the agent of consumption is not the patient, but their physician or health care provider - as much of the core evidence from health economics indeed indicates - it is possible to see a greater role for a status or positional component in driving overconsumption or misconsumption of health care. It is not difficult to see how physicians might perceive their personal professional status and prestige to be significantly impacted by their ability to offer the newest or "best" treatments, technology and equipment. Indeed, this effect would not necessarily require any link to pecuniary gain to operate. If a professional culture exists which sees access to the latest technologies and interventions as intrinsically representing "best practice", concern for professional status alone could provide a powerful incentive to overtreat. Indeed, Pita Barros, Gouveia Pinto \& Machado (1999) 
used a simple game theory model to explain how excessive investment in and use of technology could occur when health care providers use medical technology as a proxy signal for their (intrinsically unobservable) true quality and skill ("identity signalling"). They then explained how this could lead to overconsumption of health care and the adoption of technologies of limited or poor cost-effectiveness. It seems plausible to argue that some of the tendencies towards overtreatment described above (especially the "medical arms race") could be explained in part by "status races" within the medical profession.

\section{Discussion - Synthesising Economic Perspectives on Overconsumption}

This review has considered a range of perspectives on overconsumption, from health economics, behavioural economics and ecological economics. A synthesis of its most important findings can be summarised as follows. The long-standing tradition of health economics research since the 1960s has provided clear evidence that physicians do not act as perfect agents for patients, and that the provision of unnecessary services under certain circumstances is one manifestation of this imperfection. The behavioural economics evidence augments this finding with a rich set of insights on why actual practice may depart from that which an "evidence-based" approach (the presumed basis for any perfect agency relationship) would prescribe. In 
particular, it provides strong explanations of why cognitive biases, habits and heuristics frequently crowd out "evidence-based" practice, in ways that may be challenging to overcome. Moreover, behavioural findings on health professionals' strategies to deal with uncertainty and to avoid potential regret provide powerful explanations of why overuse and overtreatment may frequently appear to be the "rational" choice in clinical decision-making, even when they cause harm to patients. Meanwhile, status or positional competition can, when run through the principal-agent relationship in health care, provide a further possible force driving overuse. Figure 1 attempts to illustrate some of the potential relationships between the explanations identified by this review, displaying them in a space reflecting i) the extent to which decisions reflect imperfect agency or simply imperfect knowledge, and ii) the extent to which decisions are driven more strongly by individual or market / structural factors. This preliminary overview suggests the possibility of fertile territory for further investigation.

Insert Figure 1 here.

Synthesising perspectives from health economics, ecological economics and the sustainable consumption literature appears to be a novel approach to considering health care overconsumption. This paper therefore represents the start of a broader discussion on the economics of overconsumption in health care. It has shown that the complex of health care concepts grouped under the banner of "too much medicine" (i.e. overdiagnosis, overtreatment, 
and overutilisation etc.) share the critical features of misconsumption (Princen, 1999) - that is, individual-level consumption decisions which do not, in fact, enhance individual well-being. It also shows that several of the traditional fields of investigation within health economics (i.e. uncertainty and imperfect information, the agency relationship in health care, moral hazard, supplier induced demand etc.) have some ability to explain aspects of overconsumption in health care. However, it is striking that the health economics research in these areas has had little to say about when these phenomena may be harmful for patients, with only Labelle et al (1994) directly addressing this question in detail. In contrast, the central concern of the "too much medicine" approach is with the potential for harm caused by unnecessary care, just as the overconsumption / misconsumption perspectives are concerned with welfare-destroying consumption. At the same time, the fundamental importance of the principal-agent relationship in health care introduces a complexity not considered in the general sustainable consumption literature. Its incorporation may provide powerful additional insights on how and why apparently rational individual consumption decisions can ultimately result in misconsumption.

Implicit in the very notion of overconsumption is an excess of actual consumption beyond some underlying, lower level of genuinely beneficial or sustainable consumption. Key characteristics of health care (Arrow, 1963) tend strongly towards a situation in which market outcomes alone cannot effectively resolve the problem of "how much is enough". Arguably, health 
care thus represents a particularly clear case of a more pervasive tension between "efficiency" and "sufficiency" (Princen 2003). This is recognised in health care; as noted, levels of desirable treatment are to some degree proscribed either through reference to "best practice" and "need" (as mediated by evidence or expert opinion) or potentially through the application of costeffectiveness thresholds, rather than by market outcomes alone. Yet concepts of "need" will ratchet upwards in lockstep with technology unless an external constraint is applied; and how best to set cost-effectiveness thresholds remains a significantly contested debate amongst both health economists and policy makers (Cairns 2016).

This exercise also suggests that some of the more traditional instruments that policy makers might reach for to tackle the problem of overuse in health care may prove to be less reliable or effective than we might wish. Financial measures such as copayments and deductibles to combat moral hazard, or provider payment incentives or disincentives can and do reduce utilisation but their ability to discriminate between inappropriate and appropriate care remains weak. Competition must be handled with care, given the strong suggestion that it might frequently tend towards increased rather than decreased utilisation levels. On the other hand, traditional behaviour change interventions aimed at clinical decision-making (e.g. clinical guidelines, decision algorithms etc) may also disappoint, given the powerful countervailing forces revealed by the behavioural research identified above. 
This review also clearly illustrates the importance of understanding the behavioural factors that drive overuse in clinical decision-making. Many complex mechanisms appear to be at work, implying that multi-factorial responses will almost certainly be necessary to make progress. The sustainable consumption literature frequently focuses on the need for underlying changes in culture and values as a necessary precursor for major changes in consumption behaviour, with the implication that shorter-term "nudges" are unlikely reduce consumption effectively. Given the nature of health care, the analogous approach in this sector may in fact require significant changes to the professional norms and culture of the health professions. Princen (2003) offers a number of what he calls "sufficiency principles", which he suggests could guide cultural changes away from excess consumption. Two may be directly relevant for health care, namely restraint ("...a behavioural tendency towards using less than is physically / technically / legally / financially possible") and the precautionary principle (whereby “...corrective action is warranted in the face of critical environmental threats even when scientific evidence is not conclusive") (Princen 2003, p. 46). These principles might imply efforts to build a medical culture which values "watchful waiting" more highly than presumptive action or heroic intervention; which requires a higher burden of proof that technologies will be beneficial in any particular group of patients; and where the harm caused through overtreatment is viewed just as seriously as that caused by failure to treat. 
This review also suggests that cost-effectiveness analysis and Health Technology Assessment (HTA) has the potential to play an important role in addressing the problem of overuse. Cost-effectiveness analysis seems likely to continue to provide a robust and flexible tool for informing health care resource prioritisation and allocation decisions, which could allow the accommodation of a more robust approach to the harms of overtreatment, and potentially could reflect environmental or other negative externalities more fully. However, while HTA remains overwhelmingly focused on adoption (Bryan, Mitton \& Donaldson 2014), it is likely to fail to deter much of the pressure which is, in fact, leading to overutilisation. The behavioural literature provides quite compelling explanations of the factors which may drive overuse of established interventions, especially "indication creep" (Djulbegovic \& Paul 2011). HTA can only impact on this problem if it focuses much more actively on the management and reassessment of existing technologies, with a significantly raised bar to prevent this "creep" towards new populations or lower clinical thresholds. This would require a finer-grained ability to measure and estimates costs and effects in different sub-populations, which may have significant implications for the kind of populations in which interventions are trialled. Alternatively, a more pragmatic approach might combine a stronger drive to reduce optimism bias in modelling and analysis with a reduced willingness to extrapolate evidence from one population group or indication to another - effectively a more rigorous application of the precautionary principle, in order not to give potentially harmful overuse the benefit of the 
doubt. Both would represent more active regulation of "off-label" use and technology diffusion.

More broadly, it is proposed that there may be real value in developing an inter-disciplinary collaboration between health economics and ecological economics. This review has shown that the particular characteristics of health care make it a potentially important sectoral exemplar of concepts from ecological economics (e.g. "uneconomic growth", misconsumption and overconsumption). Conversely, concepts from ecological economics have potential value in examining health care (e.g. positional consumption). Health care's sheer scale requires the project of ecological economics to develop a better understanding of this sector, so that sustainable policies at the macro level support the best possible outcomes for human health. Overall, the findings of this review suggest that viewing the problem of health care overconsumption through a variety of economic lenses can provide important insights to help guide future responses to this problem, and can bring potentially rich insights to advance the policy and research debates in this field.

Some important limitations to this study need to be recognised. First, this paper does not attempt to provide a systematic review of the very broad and heterogeneous literature under consideration. Its purpose is simply to identify a range of relevant concepts and to commence a discussion on how they 
might relate to each other, not to provide a definitive review of the evidence in any given field.

A second important limitation relates to the strong focus in the literature reviewed towards evidence from developed countries. The vast majority of the available evidence on overuse of health care relates to developed countries; and within that literature, there is a strong bias towards evidence from the United States of America. Caution is therefore needed in generalising findings and implications across countries, and - in particular -in making assumptions regarding the (un)importance of the misconsumption of health care in developing countries.

Finally, this review has not attempted to quantify the scale of overconsumption in health care. To do so would require extensive additional effort, well beyond the scope of this initial, conceptual paper. This additional work would also be necessary to allow quantification of the extent to which health care might contribute to "uneconomic growth" in aggregate terms. Developing quantitative estimates of health care overconsumption would therefore appear to be an important area for further research, from both the health and ecological economics perspectives. 


\section{References}

Arrow, K 1963, 'Uncertainty and the welfare economics of medical care', American Economic Review, vol. 53, no. 5, pp. 941-973.

Arrow, K, Dasgupta, P, Goulder, L, Daily, G, Ehrlich, P, Heal, G, Levin, S, Maler, KG, Schneider, S, Starrett, D \& Walker, B 2004, 'Are we consuming too much?', Journal of Economic Perspectives, vol. 18, no. 3, pp. 147-172.

Beckman, HB 2011, 'Lost in translation: physicians' struggle with cost-reduction programs', Annals of Internal Medicine, vol. 154, no. 6, pp. 430-433.

Behnke, LM, Solis, A, Shulman, SA \& Skoufalos, A 2013, 'A Targeted Approach to Reducing Overutilization: Use of Percutaneous Coronary Intervention in Stable Coronary Artery Disease', Population Health Management, vol. 16, no. 3, pp. 164168.

Boulding, KE 1966, 'The concept of need for health services', The Millbank Memorial Fund Quarterly, vol. 44, no. 4, pp. 202-223.

Bryan, S, Mitton, C \& Donaldson, C 2014, 'Breaking the addiction to technology adoption', Health Economics, vol. 23, pp. 379-383.

Bundorf, MK 2016, 'Consumer directed health plans: a review of the evidence', Journal of Risk and Insurance, vol. 83, no. 1, pp. 9-41.

Buntin, MB, Haviland, A, McDevitt, R \& Sood, N 2011, 'Healthcare spending and preventive care in high-deductible and consumer-directed health plans', American Journal of Managed Care, vol. 17, no. 3, pp. 222-230.

Busfield, J 2015, 'Assessing the overuse of medicines', Social Science and Medicine, vol. 131, pp. 199-206.

Cairns, J 2016, 'Using Cost-Effectiveness Evidence to Inform Decisions as to which Health Services to Provide', Health Systems and Reform, vol. 2, no. 1, pp. 32-38.

Carter, SM, Rogers, W, Heath, I, Degeling, C, Doust, J \& Barratt, A 2015, 'The challenge of overdiagnosis begins with its definition', British Medical Journal, vol. 350, p. h869.

Chan, K, Chang, E, Nassery, N, Chang, HY \& Segal, JB 2013, 'The state of overuse measurement: a critical review', Medical Care Research and Review, vol. 70, no. 5, pp. 473-496.

Clark, AE, Frijters, P \& Shields, MA 2008, 'Relative income, happiness and utility: an explanation for the Easterlin paradox and other puzzles', Journal of Economic Literature, vol. 46, no. 1, pp. 95-144. 
Daly, HE 2005, 'Economics in a full world', Scientific American, vol. 293, no. 3, pp. $100-+$.

Daly, HE, Czech, B, Trauger, DL, Rees, WE, Grover, M, Dobson, T \& Trombulak, SC 2007, 'Are we consuming too much - for what?', Conservation Biology, vol. 21, no. 5, pp. 1359-1362.

Dasgupta, P 2010, 'Nature's role in sustaining economic development', Philosophical Transactions of the Royal Society B, vol. 365, pp. 5-11.

Deber, R, Hollander, MJ \& Jacobs, P 2008, 'Models of funding and reimbursement in health care: a conceptual framework', Canadian Public Administration, vol. 51, no. 3, pp. 381-405.

Devers, KJ, Brewster, LR \& Casalino, LP 2003, 'Changes in hospital competitive strategy: a new medical arms race?', Health Services Research, vol. 38, no. 1, pp. 447-469.

Djulbegovic, B \& Paul, A 2011, 'From efficacy to effectiveness in the face of uncertainty: indication creep and prevention creep', Journal of the American Medical Association, vol. 305, no. 19, pp. 2005-2006.

Dranove, D 1988, 'Demand inducement and the physician/patient relationship', Economic Inquiry, vol. 26, no. 2, pp. 281-298.

Dranove, D, Shanley, M \& Simon, C 1992, 'Is hospital competition wasteful?', RAND Journal of Economics, vol. 23, no. 2, pp. 247-262.

Drummond, M, Schulper, M, Claxton, K, Stoddart, G \& Torrance, G 2015, Methods for the economic evaluation of health care programmes, Fourth Edition edn, Oxford University Press, Oxford.

Duckett, S, Breadon, P, Romanes, D, P, F \& Nolan, J 2015, Questionable care: Stopping ineffective treatments, Grattan Institute.

Duckett, SJ, Breadon, P \& Romanes, D 2015, 'Identifying and acting on potentially inappropriate care', Medical Journal of Australia, vol. 203, no. 4, pp. 183-183.

Dupor, B \& Liu, WF 2003, 'Jealousy and equilibrium overconsumption', American Economic Review, vol. 93, no. 1, pp. 423-428.

Elshaug, AG, Hiller, JE, Tunis, SR \& Moss, JR 2007, 'Challenges in Australian policy processes for disinvestment from existing, ineffective health care practices', Australia New Zealand Health Policy, vol. 4, p. 23.

Fletcher, P 2014, 'The Hungry Brain', in D Southerton \& A Ulph (eds), Sustainable consumption: multidisciplinary perspectives in honour of Professor Sir Partha Dasgupta, Oxford University Press, Oxford, pp. 141-160. 
Frank, RG 2004, Behavioral economics and health economics, National Bureau of Economic Research, Cambridge, MA.

Frick, KD \& Chernew, ME 2009, 'Beneficial moral hazard and the theory of the second best', Inquiry, vol. 46, pp. 229-240.

Gabe, J, Williams, S, Martin, P \& Coveney, C 2015, 'Pharmaceuticals and society: power, promises and prospects', Social Science and Medicine, vol. 131, pp. 193198.

Hirsch, F 1977, Social Limits to Growth, Routledge \& Kegan Paul, London.

Hozo, I \& Djulbegovic, B 2008, 'When is diagnostic testing inappropriate or irrational? Acceptable regret approach', Medical Decision Making, vol. 28, no. 4, pp. 540-553.

Illich, I 1976, Limits to medicine. Medical nemesis: the expropriation of health, Marion Boyars, London.

Labelle, R, Stoddart, G \& Rice, T 1994, 'A re-examination of the meaning and importance of supplier-induced demand', Journal of Health Economics, vol. 13, pp. 347-368.

Langenbrunner, JC, Cashin, C \& O'Dougherty, S 2009, Designing and implementing health care provider payment systems, How-To Manuals, The World Bank, Washington DC.

Leonard, C, Storduer, S \& Roberfroid, D 2009, 'Association between physician density and health care consumption: a systematic review of the evidence', Health Policy, vol. 91, pp. 121-134.

Macdonald, H \& Loder, E 2015, 'Too much medicine: the challenge of finding common ground', British Medical Journal, vol. 350, p. h1163.

Marcus, PM, Prorok, PC, Miller, AB, DeVoto, EJ \& Kramer, BS 2015, 'Conceptualizing overdiagnosis in cancer screening', Journal of the National Cancer Institute, vol. 107, no. 4.

Marmot, MG, Altman, DG, Cameron, DA, Dewar, JA, Thompson, SG, Wilcox, M \& Independent, UKPBCS 2012, 'The benefits and harms of breast cancer screening: an independent review', Lancet, vol. 380, no. 9855, pp. 1778-1786.

Moynihan, R, Henry, D \& Moons, KGM 2014, 'Using Evidence to Combat Overdiagnosis and Overtreatment: Evaluating Treatments, Tests, and Disease Definitions in the Time of Too Much', Plos Medicine, vol. 11, no. 7.

O'Callaghan, G, Meyer, H \& Elshaug, AG 2015, 'Choosing wisely: the message, messenger and method', Medical Journal of Australia, vol. 202, no. 4, pp. 175-178. 
Pauly, MV 1968, 'The economics of moral hazard: comment', American Economic Review, vol. 58, no. 3, pp. 531-537.

Peacock, SJ \& Richardson, JRJ 2007, 'Supplier-induced demand: re-examining identification and misspecification in cross-sectional analysis', European Journal of Health Economics, vol. 8, pp. 267-277.

Pita Barros, P, Gouveia Pinto, C \& Machado, A 1999, 'A signalling theory of excessive technological adoption', Health Care Management Science, vol. 2, pp. 117-123.

Princen, T 1999, 'Consumption and environment: some conceptual issues', Ecological Economics, vol. 31, pp. 347-363.

- - 2003, 'Principles for sustainability: from cooperation and efficiency to sufficiency', Global Environmental Politics, vol. 3, no. 1, pp. 33-50.

Rabin, M 1998, 'Psychology and economics', Journal of Economic Literature, vol. 36, no. March 1998, pp. 11-46.

Rabin, M \& Schrag, JL 1999, 'First impressions matter: a model of confirmatory bias', Quarterly Journal of Economics, pp. 37-82.

Robertson, C, Rose, S \& Kesselheim, AS 2012, 'Effect of financial relationships on the behavior of health care professionals: a review of the evidence', Journal of Law, Medicine and Ethics, vol. 40, no. 3, pp. 452-466.

Robinson, JC \& Luft, HS 1985, 'The impact of hospital market structure on patient volume, average length of stay and the cost of care', Journal of Health Economics, vol. 4, pp. 333-356.

Schwartz, AL, Landon, BE, Elshaug, AG, Chernew, ME \& McWilliams, JM 2014, 'Measuring Low-Value Care in Medicare', JAMA Internal Medicine, vol. 174, no. 7, pp. 1067-1076.

Scitovsky, T 1992, The joyless economy: the psychology of human satisfaction, Revised Edition edn, Oxford University Press, New York.

Segal, JB, Nassery, N, Chang, HY, Chang, E, Chan, K \& Bridges, JFP 2015, 'An Index for Measuring Overuse of Health Care Resources With Medicare Claims', Medical Care, vol. 53, no. 3, pp. 230-236.

Sorman, A \& Giampietro, M 2013, 'The energetic metabolism of societies and the degrowth paradigm: analyzing biophysical constraints and realities', Journal of Cleaner Production, vol. 38, pp. 80-93.

Stano, M 1987, 'A clarification of theories and evidence on supplier-induced demand for phsyician services', Journal of Human Resources, vol. 22, no. 4, pp. 611-620. 
Thaler, R 1980, 'Toward a positive theory of consumer choice', Journal of Economic Behavior \& Organization, vol. 1, pp. 39-60.

Welch, HG, Schwartz, LM \& Woloshin, S 2011, Over-diagnosed: making people sick in the pursuit of health, Beacon Press, Boston, Mass. 